\title{
REFÚGIO E REALIDADE: DESAFIOS DA DEFINIÇÃO AMPLIADA DE REFÚGIO À LUZ DAS SOLICITAÇÕES NO BRASIL
}

\author{
Aryadne Bittencourt Waldely* \\ Bárbara Gonçalves das Virgens** \\ Carla Miranda Jordão de Almeida***
}

O presente artigo visa analisar como a noção de grave e generalizada violação de direitos humanos e a definição de refugiado se relacionam no reconhecimento das solicitações de refúgio no Brasil sobre casos individuais de violência. O objetivo é propor uma interpretação mais inclusiva e abrangente do conjunto normativo acerca da temática do refúgio. Este exercício se desenvolve a partir da análise de um caso concreto de um atleta oriundo da República Democrática do Congo que teve sua vida, sua liberdade e sua segurança em risco em seu país de origem, mas cuja narrativa, em princípio, não se enquadra na jurisprudência para os casos de reconhecimento de refúgio pelo governo brasileiro. O interesse central deste trabalho é, portanto, problematizar alguns entre tantos aspectos suscitados pelas lacunas de aplicabilidade do arcabouço jurídico para a temática do refúgio.

Palavras-chaves: refúgio, direitos humanos, direito dos refugiados, direito internacional dos direitos humanos, República Democrática do Congo.

\section{Introdução}

O presente artigo tem o intuito de problematizar um dos tantos aspectos suscitados pela lacuna de aplicabilidade do arcabouço jurídico para a temática do refúgio no Brasil. Pensa-se a questão a partir do recorte do caso concreto de um solicitante de refúgio que neste momento aguarda a resposta de seu pedido por parte do governo brasileiro.

\footnotetext{
Mestranda em Direitos Humanos, Sociedade e Arte na UFRJ. Rio de Janeiro/Brasil.

${ }^{* *}$ Mestre em Cooperação e Desenvolvimento pela Universidade de Paris 3 - Sorbonne Nouvelle. Rio de Janeiro/Brasil.

${ }^{* * *}$ Mestranda em Direitos Humanos e Democracia pelo European Inter-University Centre for Human Rights and Democratisation. Rio de Janeiro/Brasil.
} 
Trata-se de um órfão de guerra que se viu sozinho no mundo após a morte de todos os seus familiares. Nacional de um Estado em que o conflito, a pobreza, a instabilidade política e a fragilidade democrática são apenas alguns dos elementos que o caracterizam, depositou no esporte as esperanças de uma vida melhor e um pouco mais afastada de tanto sofrimento. Contudo, como se não bastasse o passado que ainda o assombra, no mesmo esporte em que encontrou oportunidades teve os sonhos destruídos ao sofrer maus-tratos e humilhação por parte de seu treinador, sendo obrigado a buscar no Brasil uma chance definitiva de recomeçar, mais uma vez, sua vida. Sua narrativa é densa, dramática e com diferentes vetores de vulnerabilidade. Não há dúvidas de que este ser humano merece a proteção de algum Estado nacional que seja comprometido com as diretrizes internacionais dos Direitos Humanos, como o Brasil.

Apesar disso, surpreende dizer que o caso em tela não reproduz a ordem jurídica contemporânea expressa no direito brasileiro comum acerca do tema. Como será demonstrado, a indefinição do agente perseguidor e do tipo de perseguição se tornam um empecilho para que o reconhecimento do refúgio seja defendido. Tendo esta equação como ponto de partida e com a certeza da ameaça aos bens jurídicos da vida, segurança e liberdade, propõe-se, então, pensar como a noção de grave e generalizada violação de direitos humanos e a definição de refugiado se relacionam no reconhecimento das solicitações de refúgio no Brasil sobre casos individuais de violência.

Afim de melhor explorar esta questão, o presente trabalho tem como referência a narrativa do solicitante, considerando os diferentes aspectos objetivos e subjetivos presentes em seu discurso. Sabendo-se que este método não representa uma forma discursiva neutra e, por isso, não deve ser vista como representação direta da realidade, nos apropriamos de seu relato, analisando-o a partir do contexto no qual ele está inserido: daí a importância das informações referentes ao seu país de origem e às práticas legais referentes à concessão de refúgio no Brasil. Segundo Hayden White, os fatos presentes em uma narrativa não falam por si, no entanto, quando problematizados, eles revelam aspectos fundamentais para a compreensão de certos fenômenos sociais. É nesta perspectiva que desenvolvemos, a seguir, nossa análise ${ }^{1}$.

\section{O conceito de refúgio e a aplicabilidade da legislação nacional}

"Uma pessoa não se torna refugiado por que é reconhecida como tal, mas é reconhecida como tal porque é refugiado" ${ }^{2}$. E o que é ser refugiado?

\footnotetext{
WHITE, Hyden. El contenido de la forma: narrativa, discurso y representación histórica, p. 20.

2 ACNUR. Manual de Procedimentos e Critérios para a Determinação da Condição de Refugiado: de acordo com a Convenção de 1951 e o Protocolo de 1967 relativos ao estatuto dos refugiados, p. 10, parágrafo 28 .
} 
Alguns responderiam de pronto o que preceitua a Convenção Relativa ao Estatuto dos Refugiados de 1951, em seu artigo $1 \mathrm{~A}^{3}$, que, basicamente, elenca fundados temores de perseguição por motivos de raça, religião, nacionalidade, ou pertencimento a determinado grupo social ou, ainda, por conta de opiniões políticas como definidores. De fato, esta é a definição clássica formalizada à luz da necessidade de sistematizar um mecanismo de proteção internacional capaz de amparar o enorme e inédito número de pessoas perseguidas vítimas da Segunda Guerra Mundial.

O refúgio é um instituto de proteção à vida decorrente de compromissos internacionais confirmados pelo Brasil em sua constituição nacional ${ }^{4}$. Cumpre frisar que o refúgio não é um instituto jurídico que nasce da vontade de um Estado soberano de ofertar proteção a um cidadão estrangeiro que se encontra em seu território - é tão somente o reconhecimento de um direito pré-existente à demanda formal do indivíduo.

Questionamentos ao conceito de refugiado há tempos já são levantados frente à insurgência de novos desafios impostos à comunidade internacional, como indica o número crescente de pessoas deslocadas em decorrência de miséria extrema ou mesmo os migrantes por razões ambientais ${ }^{5}$. É notório que esta definição não se adapta facilmente à magnitude, escala e natureza de muitos dos atuais conflitos ou situações de violência e dos movimentos dos refugiados, evidenciando que o conceito de refugiado não é e não pode ser considerado um conceito estático, tal qual nenhuma norma ou conceito jurídico o é. O Direito é, pois, uma expressão constante da experiência social de modo que as normas refletem comportamentos e fatos sociais e não o contrário, sob risco de ficarem caducas e ineficazes ${ }^{6}$.

Assim, é preciso ter atenção aos casos empíricos que evidenciam que há muitas outras pessoas deslocadas que não estão incluídas nas atuais definições de refugiado, todavia também não estão excluídas. Cite-se aquelas pessoas que deixaram seus países de origem em razão de situações terríveis como miséria econômica generalizada, fragilidade democrática e tantas outras formas de violação ou restrição a direitos fundamentais, mas que não são consideradas oficialmente refugiadas, vez que estas situações não são vislumbradas no regime atual .

Conjuntamente com o art. 1, §1 do Protocolo Sobre o Estatuto dos Refugiados de 1967.

4 Art $4^{\circ}$ II e art $5^{\circ}$ LXXVIII, em especial $\S 2^{\circ}$ e $3^{\circ}$, da Constituição da República Federativa do Brasil de 1998.

5 ACNUR. Número de deslocados forçados ultrapassada 50 milhões pela primeira vez desde a Segunda Guerra Mundial. Disponível em: <http://www.onu.org.br/numero-de-deslocados-forcadosultrapassa-50-milhoes-pela-primeira-vez-desde-a-segunda-guerra-mundial/> . Último acesso em: 06.10.2014.

6 Para mais referências REALE, Miguel. Filosofia do Direito. São Paulo: Saraiva, 1999.

7 Cite-se como exemplo a noção de survival migrants conceituados como pessoas cujo status está na lacuna entre a dicotomia do conceito de refugiados e o de migrantes econômicos voluntários. Para mais referência BETTS, Alexander. Survival Migration: A New Protection Framework. Global 
Torna-se, pois, evidente a necessidade de flexibilização do regime para melhor adequação à realidade atual e, mais: que este seja um esforço e um exercício contínuo para que o Direito acompanhe as alterações, desenvolvimento e/ou possíveis evoluções da sociedade a que se aplica. O próprio Estado brasileiro já manifestou expressamente sua preocupação com as lacunas de proteção em relação a novas situações e é preciso continuar a luta conjunta com todos os atores envolvidos em prol de ações concretas nesse sentido ${ }^{8}$.

Com efeito, o Brasil foi o primeiro país do cone sul a ratificar a Convenção de 1951 e a sancionar uma lei nacional que tratasse do tema - a Lei n. 9.474 de 22 de julho de 1997, que define os mecanismos de implementação do Estatuto dos Refugiados de 1951 e determina outras providências, como a criação do Comitê Nacional para os Refugiados (CONARE) - um órgão de deliberação colegiada e tripartite responsável, em primeira instância, pela elegibilidade do refúgio no país.

Ao CONARE cabe, inter alia, deliberar sobre os casos que se apresentam ${ }^{9}$ com base na constituição brasileira de 1988, na Convenção de 51, no Protocolo de 67 e ainda levando em conta demais fontes de Direito Internacional dos Refugiados, como constam nos dispositivos da Convenção da Organização

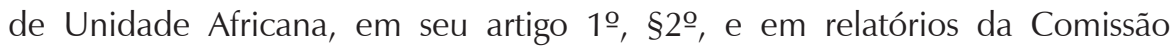
Interamericana dos Direitos Humanos. Além disso, é previsto pelo ordenamento nacional ${ }^{10}$ que todos os dispositivos sejam interpretados harmonicamente com a Declaração Universal dos Direitos Humanos de 1948 e todos os demais dispositivos pertinentes ao instrumento internacional de proteção aos direitos humanos com o qual o Governo brasileiro estiver comprometido.

Destaque-se assim que afora o que é definido no artigo $1^{\circ}$ da Lei 9.474/97 que conjuga a definição clássica de refugiados com o entendimento ampliado estabelecido pela Declaração de Cartagena de 1984 ${ }^{11}$, é necessário que se faça sempre um estudo individual dos casos e uma análise teleológica de todos os princípios, dispositivos e compromissos legais assumidos pelo Brasil, tendo em mente essencialmente que acima de qualquer aparato burocrático tem-se uma vida em jogo.

Governance: A Review of Multilateralism and International Organizations: July-September 2010, v. 16, n. 3, p. 361-382.

8 Blog O Estrangeiro. Cartagena + 30 = Mais Expectativas. 23.03.2014. Disponível em: <http:// oestrangeiro.org/2014/03/23/cartagena-30-mais-expectativas> . Último acesso em: 26.08.2014.

9 Competência determinada pelo artigo 12 da Lei 9.474/97.

${ }^{10}$ Artigo 48 da Lei 9.474/97.

11 A Declaração de Cartagena traz a noção de que o reconhecimento do status de refugiado deve ser também garantido àqueles que devido a uma grave e generalizada violação de direitos humanos foram forçados a deixar seu país de origem para buscar refúgio em outra nação. 
No balanço geral, ainda que o Brasil tenha uma avançada legislação sobre refugiados, a ausência de uma política nacional de migração e refúgio dificulta pensar nos casos cada vez mais complexos que se apresentam face à realidade global. Além disso, o país não apresenta estrutura e nem programas claramente definidos que estimule o acolhimento e a integração de forma digna e humana ${ }^{12}$. Espera-se que os debates atuais acerca de uma nova lei de migração, os encontros nacionais e internacionais sobre migração e refúgio sediados no país neste ano de 2014, aliados ao incansável trabalho da sociedade civil, tenham frutos positivos neste sentido em um futuro próximo.

\section{Contextualização do caso concreto}

Na elaboração de um parecer jurídico que sustente o reconhecimento do refúgio para o caso concreto apresentado, as declarações do solicitante devem ser analisadas no contexto da situação concreta e dos antecedentes relevantes. Como dito, uma primeira análise levaria facilmente a constatar perseguição individual em que o jovem em questão teria sido vítima de maus-tratos em decorrência de suas atividades como atleta. Desta forma, esta situação dificilmente justificaria o reconhecimento do status de refugiado do solicitante, pois ainda que este ato de brutalidade seja condenável, ele não corresponde aos critérios legais necessários para a proteção do rapaz. Considerando, porém, que esta narrativa está inserida em um contexto de grave e generalizada violação de Direitos Humanos na República Democrática do Congo, onde a gravidade do conflito tem provocado o desmantelamento das estruturas política, econômica e social, constata-se que este é um caso emblemático que remete à importância de flexibilização das diretrizes para a definição dos casos de refúgio.

Nesta ótica, abordar-se-á de forma mais detalhada a trajetória deste rapaz, bem como a história de seu país, evidenciando como a desestruturação do Estado pela guerra aumenta a vulnerabilidade de sua população, criando um contexto de grave e generalizada violação de Direitos Humanos.

A história da República Democrática do Congo (RDC) foi marcada por diversos conflitos resultantes das numerosas tensões étnicas e das disputas por poder e acesso às riquezas naturais existentes nesta região; situação agravada pela instabilidade e pela violência presente nos países vizinhos. A primeira guerra do Congo teve início em 1996 e seu epicentro foi a região dos Grandes Lagos, zona de fronteira com o Burundi e Ruanda. As razões para a crise iniciada em outubro daquele ano são múltiplas e complexas. Mas, em termos gerais, considera-se que o estopim do conflito foram os levantes dirigidos por Laurent-

12 SILVA, Cesar Augusto da; RODRIGUES, Viviane Mozine. Refugiados: Os Regimes Internacionais de Direitos Humanos e a Situação Brasileira. 
Désiré Kabila, sob o auspício ruandês, para a dissolução do governo ditatorial de Mobuto. Após sete meses de disputas violentas e mais de 200.000 mortos, o líder opositor se autoproclamou presidente da $\mathrm{RDC}^{13}$.

Sua chegada ao poder, no entanto, não significou o fim da instabilidade no país, ao contrário, as disputas étnicas e entre os diferentes grupos armados por poder e riquezas minerais ${ }^{14}$ continuaram ocasionando uma série de conflitos em que a população é, até os dias de hoje, a principal vítima. Segundo dados oficiais do ACNUR ${ }^{15}$, os níveis alarmantes de violência provocaram o aumento significativo de deslocamentos internos neste país, chegando a 2,9 milhões o número de pessoas obrigadas a abandonar suas casas em razão do conflito.

É, então, a partir deste cenário de guerra que se retoma a trajetória de vida do jovem congolês. Nascido em Bukavu, capital do Kivu-Sul, a vida de Nkanza ${ }^{16}$ foi abalada pelo conflito quando, ainda criança, seus pais foram mortos durante as batalhas da primeira guerra do Congo. Segundo relatório publicado pela organização Reporters Without Borders, sua família faz parte de uma triste estatística: Bukavu é uma das cidades mais violentas da África central, alvo de conflitos que deixaram mais de 4 milhões de mortos entre os anos de 1997 e $2007^{17}$.

Órfão, não se recorda se tinha irmãos, lembra-se apenas do avião que o levou junto com outras crianças à capital, Kinshasa, onde cresceu em um abrigo do governo por não ter nenhum familiar com quem viver. Neste abrigo, foi-lhe oferecida uma profissão. Entre a mecânica e o judô, o jovem escolheu ser um atleta, tendo como sonho competir por seu país. O que parecia uma saída à violência à qual tinha estado submetido até então, o colocou, mais uma vez, em situação de risco. Se por um lado, o esporte lhe permitiu conhecer outros países (Marrocos, Senegal, Moçambique e Brasil, onde finalmente conseguiu escapar e pedir refúgio), por outro, seus anos de treinamento foram marcados por maus-tratos. Sem nunca ter recebido para representar a RDC, afirma ter sido

${ }_{13}$ BUKASA, Eric. La RDC et le processus d'intégration des pays de Grands Lacs comme voie de sortie de la crise sécuritaire régionale. Disponível em: < http://www.memoireonline.com/12/08/1724/m La-RDC-et-le-processus-dintegration-des-pays-des-Grands-Lacs-comme-voie-de-sortie-de-lacrise-secur2.html>. Último acesso em: 29.08.2014.

${ }^{14}$ A RDC possui algumas das maiores reservas do mundo dos seguintes minerais: cobre, cobalto, ouro, diamantes, zinco, estanho e tungstênio. Informações disponíveis em: < https://www.cia.gov/ library/publications/the-world-factbook/geos/cg.html>. Último acesso em: 12.10.2014.

${ }^{15}$ UNHCR. Democratic Republic of Congo, 2014 country operations profile. Disponível em: <http:// www.unhcr.org/pages/49e45c366.html> Último acesso em 12.10.2014.

${ }^{16}$ Nome fictício devido à confidencialidade do processo.

17 Reporters without borders. Bukavu, murder city. An investigation into the murders of journalists in the capital of Sud-Kivu. Refworld. 18.03.2009. Disponível em: <http://www.refworld.org/cgi$\mathrm{bin} /$ texis/vtx/rwmain?page $=$ search\&docid $=49 \mathrm{c} 38 \mathrm{ffd} 2 \&$ skip $=0 \& q u e r y=k i v u \% 20$ sud $>$. Último acesso em: 28.07.2014. 
submetido a situações degradantes e a punições severas que nada se assemelham à rigidez presente na vida de qualquer atleta. Antes, ele já havia sido vítima de castigos físicos, além de presenciar o aprisionamento de seus colegas em jaulas devido a derrotas em torneios importantes.

A complexidade deste caso é evidenciada quando se considera que em um contexto de guerra, como o vivido na RDC, o limiar entre a luta armada, a política e a vida cotidiana da população é tênue. Ao se observar a trajetória de outros judocas e a organização da confederação nacional de judô, constata-se que ambas estão vinculadas à vida política e submetidas à violência generalizada que atinge todo o país. Embora não tenha sido possível a confirmação dos maus-tratos aos atletas por parte de seus treinadores, várias evidências foram encontradas quanto à má gestão da Federação Nacional Congolesa de Judô (FENACOJU), e sobre o envolvimento de seus dirigentes em atividades políticas ilegais. Estas constatações demonstrariam, portanto, que a situação de vulnerabilidade à qual o solicitante foi exposto está vinculada a guerra em seu país.

Quanto aos problemas de gestão da Federação Nacional Congolesa de Judô, desde 2010, várias acusações foram feitas a Francis Bimuala, então presidente da instituição. Segundo depoimento de alguns atletas, o dirigente se apropriava das verbas destinadas ao esporte, além de estimular conflitos internos entre os judocas. O ápice da crise envolvendo Francis Bimuala se deu durante os Jogos da Francofonia, em 2013, quando o judô foi proibido de participar, em razão de disputas internas. Nesta ocasião, o atleta Cédric Mandembo havia fugido. Ademais, a divisão entre as lideranças da FENACOJU provocou a intervenção do Comitê Olímpico Congolês que deveria ser o responsável pela seleção dos atletas que representariam o país na competição. Frente à recusa do dirigente da instituição em aceitar a intervenção, o esporte acabou sendo excluído do evento.

As acusações a Francis Bimuala não se restringem ao seu trabalho frente à federação nacional de judô. Segundo o jornalista Freddy Mulongo, o presidente da FENACOJU fomentou ataques contra opositores políticos da União para a Democracia e para o Progresso Social (UDPS), além de estar à frente dos milicianos kulunas $^{18}$. Existem, ainda, fortes indícios de que Francis Bimuala era

${ }^{18}$ Similares a gangues urbanas, os Kulunas são grupos formados por jovens e crianças, em sua maioria, órfão de guerra, responsabilizados por parte da violência e das altas taxas de criminalidade em Kinshasa. Segundo relatório publicado em 2013 pela Missão das Nações Unidas para a Estabilização da República Democrática do Congo (MONUSCO) em parceria com a UNICEF, o início da operação Likofo (ou 'soco') desenvolvida pelo governo de Kabila, teria coincidido com a desaparição e assassinato de crianças e adolescentes de comunidades da capital do país. OCHA: UNICEF and MONUSCO are concerned by reports on the disappearance and assassination of youth and children in Kinshasa. 27 de Novembro de 2013. Disponível em: <http://reliefweb.int/report/ democratic-republic-congo/unicef-and-monusco-are-concerned-reports-disappearance-and $>$. último acesso em: 12.10.2014. 
agente da Agência Nacional de Informações, e que ele tinha tido por missão (dada por parte do partido governista, PPRD) matar militantes opositores da UDPS ${ }^{19}$. Vale lembrar, que o jornalista e autor das denúncias enumeradas anteriormente também foi vítima de perseguição devido às restrições a liberdade de expressão que vigoram na RDC, o que o obrigou a fugir de seu país.

As atividades políticas nas quais Francis Bimuala está envolvido, bem como o uso político da confederação de judô colocam em evidência o fundado temor de perseguição alegado no caso em questão, ainda que o agente perseguidor não esteja claramente definido. Resta-nos, porém, compreender o vínculo desta perseguição à grave e generalizada violação de Direitos Humanos que atinge o país.

Como mencionado anteriormente, diversos são os grupos armados que disputam o poder e o acesso às riquezas naturais da RDC. Após anos de conflito, a principal vítima da guerra generalizada que assola o país é a própria população. O relato do jovem em questão, bem como as narrativas construídas por veículos de comunicação, Organizações Internacionais e outros solicitantes de refúgio, permitem constatar que os ataques sofridos pela população congolesa estão associados à perda do monopólio da violência pelo Estado, em virtude da usurpação do poder por diferentes grupos representantes de interesses privados. Vê-se que aqueles que estão no poder são alvo da concorrência armada das milícias locais e internacionais, o que desestabiliza toda estrutura administrativa do país, tornando o recurso às armas contra qualquer ameaça opositora; prática recorrente para a manutenção do status quo. Estes conflitos não apenas anulam a capacidade do Estado de proteger seus cidadãos, como fazem dele um dos principais perpetradores da violência ${ }^{20}$. Observa-se, assim, que o objetivo da ação pública deixa de ser o bem-estar coletivo, transformando-se em mera disputa por poder, seja ele político ou econômico.

Nesta perspectiva, toda instituição ou funcionário vinculado ao governo pode tornar-se um instrumento do conflito. No que se refere à Federação Nacional Congolesa de Judô, não apenas seu presidente estava envolvido em perseguições a opositores, como seus atletas podem ter sido compelidos a atuar politicamente. Ainda que não seja possível provar que o envolvimento político seja compulsório, sabe-se que a participação do judoca Chaleur nas eleições presidenciais de 2011 provocou tensões entre governo e oposição, expondo-o a ameaças de morte, segundo divulgado pela imprensa internacional ${ }^{21}$.

${ }^{19}$ Francis Bimuala, I'home qui a organisé I'attaque de la permanence de I'UDPS. Radio Réveil International, 09.09.2011. Disponível em: <http://reveil-fm.com/index.php/2011/09/09/1719francis-bimuala-I-homme-qui-a-organise-l-attaque-de-la-permanence-de-l-udps $>$. Último acesso em: 29.08.2014

${ }^{20}$ Análise feita considerando o sentido weberiano de Estado. Para mais referências WEBER, Max. Ciência e Política: duas vocações.

${ }^{21}$ Des membres de gangs et des enfants des rues recrutés par les partis politiques. France 24, 
Em um ciclo vicioso, todos estão expostos às mazelas da guerra ainda que não lutem por ela, pois o conflito leva à desordem política e ambos agravam a pobreza. Segundo notícias difundidas pela rádio Okapi ${ }^{22}$, veículo de comunicação da Missão das Nações Unidas para Estabilização da RDC (MONUSCO), milhares de pessoas abandonam, cotidianamente, suas casas em busca de melhores condições de vida. No entanto, estes deslocamentos massivos provocam o aumento repentino da população de alguns vilarejos, o que torna os recursos básicos insuficientes, destruindo laços tradicionais de solidariedade e estimulando disputas locais por produtos de subsistência. Seja em Kinshasa ou nos vilarejos atacados por grupos rebeldes e forças militares, mulheres são cotidianamente vítimas de violência sexual e, em alguns casos, obrigadas a cometer infanticídio. Crianças são capturadas para servir a luta armada, sem falar no drama vivido pelos órfãos do conflito, como bem exemplifica a trajetória do judoca em questão.

Neste cenário, a violência torna-se um elemento presente na vida cotidiana de grande parte da população congolesa. Desta forma, seu processo de generalização estaria associado a dois aspectos fundamentais para se compreender o impacto da guerra sobre a vida desta população: a transformação da natureza dos conflitos armados, em razão do envolvimento de civis enquanto vítimas e participantes da luta armada; e em razão da fragilidade do Estado, marcada pela ação de grupos defensores de interesses privados, em detrimento da responsabilidade social inerente aos $\operatorname{Estados}^{23}$. Considerando-se que a proteção internacional aos refugiados visa garantir a dignidade humana, promovendo o direito do indivíduo de resistir à violência à qual ele foi exposto em território nacional, a escolha do judoca em questão de abandonar a seleção de seu país durante o campeonato mundial de judô realizado no Rio de Janeiro pode ser percebido como seu único recurso para escapar do contexto de violência no qual esteve inserido até então.

Ainda que a apresentação detalhada do caso torne evidente a necessidade de proteção ao solicitante, existem algumas questões legais que, como proposto no início do presente trabalho, merecem ser elucidadas. Retomam-se, assim, alguns aspectos da legislação brasileira que permitem questionar algumas das categorizações utilizadas para o reconhecimento do refúgio no Brasil.

29.11.2011. Disponível em: <http://www.france24.com/fr/20111125-rdc-congo-electionpresidentielle-28-novembre-jeunes-PPRD-chaleur-zero-deux-kabila-scrutin/>. Último acesso em: 29.08.2014.

22 Les deplacés reclament des moyens pour retourner dans leurs villages. Rádio Okapi, 11.10.2014 Disponível em: <http://radiookapi.net/actualite/2014/10/11/minova-les-deplaces-reclament-desmoyens-pour-retourner-dans-leurs-villages/>. Último acesso em: 12.10.2014.

${ }^{23}$ TURK, Volker. Protection gaps in Europe? Persons fleeing the insdicriminate effects of generalized violence. Brussels: UNHCR, 2011. 


\section{Outras considerações e análise jurídica do caso concreto}

Pelo exposto, verifica-se que não se trata de refugiado clássico nos termos dos elementos de perseguição definidos, ao mesmo tempo em que se configura alguma forma de perseguição e de violação massiva de direitos humanos. Assim, para haver adequação ao ordenamento jurídico brasileiro, seria preciso recorrer tanto ao inciso I quanto ao inciso III, ambos do artigo 10 da Lei 9.474/97. Devido à dificuldade de adequação estrita da definição de refugiado adotada pela Convenção de Genebra de 1951 e mais amplamente pelo Brasil, este caso aponta a importância dos agentes governamentais realizarem uma interpretação mais inclusiva, como recomenda o ACNUR à luz dos propósitos humanitários e protetivos do instituto do refúgio ${ }^{24}$.

Quanto ao inciso I, certo é que a noção de "perseguição" revela seu caráter subjetivo e, por conseguinte, individual. Contudo, no estudo de caso, não há nitidez sobre quem seria o agente perseguidor dos judocas. Treinador? Estado? Federação Nacional de Judô? Ou um conjunto de todos eles? Conforme a interpretação do $\mathrm{ACNUR}^{25}$, mesmo que o agente perseguidor não seja diretamente relacionado ao Estado, configura-se perseguição que motive o refúgio se os atos forem de conhecimento ou tolerância das autoridades governamentais, ou ainda quando estas autoridades se recusam ou são incapazes de oferecer uma proteção eficaz. Todos os possíveis agentes perseguidores elencados para o caso dos judocas guardam alguma relação com o Estado, de modo a indicar minimamente a sua omissão na garantia de liberdades desses atletas. Ou seja, os danos sofridos pelos judocas congoleses foram causados pela incapacidade do Estado em protegê-los.

O motivo de perseguição por grupo social é aquele que possui menor clareza no conceito. De modo geral, abarca "pessoas cuja origem, estilo de vida e condição social são similares"26. Em analogia, pode-se considerar Nkanza como pertencente a um grupo social dos judocas devido à sua utilização política e ao tratamento degradante dispensado a ele, como apresentado anteriormente. Se por um lado o congolês recebeu tratamento similar por estar inserido no contexto do judô; por outro, não há consenso acerca do pertencimento do judoca a um grupo social específico, já que não há evidência se aquele tratamento é recebido por todos os judocas.

Dessa forma, as circunstâncias indicam que, muito mais do que perseguição individualizada, o caso dos judocas é decorrente de violência

\footnotetext{
${ }^{24}$ ACNUR. Resumen de las conclusiones sobre la interpretación de la definición ampliada de refugiado de la Declaración de Cartagena de 1984, p. 2.

25 IDEM. Manual de Procedimentos..., op. cit., parágrafo 65 referente ao item "Agentes de Perseguição".

${ }^{26}$ Ibidem, p. 18.
} 
generalizada e violação massiva de direitos humanos. Ora, Nkanza foi submetido a tratamento cruel, desumano e degradante com a conivência do poder estatal, fato este decorrente de ter sido órfão da guerra de 1996 e 1997. Com isso, apesar de não figurar as características do refugiado clássico vislumbrado pela Convenção de Genebra de 1951, há uma necessidade alarmante de acolhida deste congolês, suscitando a conveniência da definição de refugiado ser ponderada em um aspecto mais amplo para fins de proteção.

Nesse ínterim, a Declaração de Cartagena de 1984 contribui para o aumento da abrangência do instituto do refúgio, uma vez que abrange um escopo maior de pessoas necessitadas de proteção internacional que não podem encaixar-se na noção clássica de refugiado, indicando seu caráter protetivo complementar. Este desígnio foi incorporado no ordenamento jurídico brasileiro por meio do inciso III da Lei 9.474/97 que determina, inter alia, a decorrência de "grave e generalizada violação de direitos humanos" como fato motivador pra reconhecimento do status de refugiado.

De acordo com a interpretação do ACNUR sobre a Declaração de Cartagena de 1984, o propósito de contemplar proteção às pessoas que fogem de violações evidentes de direitos humanos de caráter não civil-político como pobreza extrema, violência, doenças, desnutrição e insegurança alimentar ${ }^{27}$, fortalecem o instituto de refúgio consagrado na Convenção de 1951. Isso porque a "orientação humanitária e de proteção do instrumento requer uma interpretação inclusiva, evolutiva e flexível"28 (grifo do autor).

Nesse sentido, o que deve prevalecer para ponderar a adequação de um solicitante no instituto do refúgio ou não é justamente "uma situação insuportável de violência; seja pela definição clássica ou pela definição ampliada"29. Tendo em vista a natureza objetiva da violência indiscriminada, torna-se incongruente traçar hierarquias entre as pessoas que fogem de situações equânimes. No caso da RDC, por exemplo, não há vida que possa estar segura ou liberdade que possa ser garantida. O que ocorre é que, dependendo da região e do grupo social, a situação de risco consegue ser ainda mais terrível. Ou seja, é uma diferença de grau, que remete à imprecisão do termo "grave e generalizada

27 São exemplos dos considerados efeitos indiretos dos cinco "eventos situacionais", previstos pela conclusão "3" da Declaração de Cartagena de 1984, que podem ameaçar a vida, a segurança e a liberdade dos indivíduos, motivando o reconhecimento do refúgio. Os eventos são: violência generalizada; agressão estrangeira; conflitos internos; violação massiva dos direitos humanos; e outras circunstâncias que tenham perturbado gravemente a ordem pública.

${ }^{28}$ Tradução livre do trecho original em espanhol "a orientación humanitaria y de protección del instrumento requiere una interpretación inclusiva, evolutiva y flexible" (Ibidem, p. 2).

${ }_{29}$ ALMEIDA, Guilherme Assis de. A Lei 9.474/97 e a definição ampliada de refugiado: breves considerações, p. 162. 
violação de direitos humanos", implicando tanto um aspecto qualitativo (grave) quanto quantitativo (generalizada).

Segundo o ACNUR, o termo "violência generalizada" abrange "situações caracterizadas por uma violência tão indiscriminada e generalizada ao ponto de afetar a grandes grupos de pessoas ou populações inteiras, as obrigando a fugir" ${ }^{\prime \prime 3}$. Assim, as situações de violência generalizada inevitavelmente implicam violações graves e massivas de direitos humanos. Essas situações incluem exercício de violência pelo Estado, bem como por atores não-estatais, sendo que, de uma ou de outra forma, provocam iminente risco a vida, segurança e/ou liberdade da população ${ }^{31}$ cujos efeitos nem sempre são de fácil visualização ${ }^{32}$. Não pode ser outra a conjuntura da RDC.

Devido à natureza do instituto referente à violação massiva de direitos humanos, os tratados internacionais de direitos humanos também devem embasar a proteção dos refugiados ${ }^{33}$, já que eles afetam o direito de buscar refúgio e os direitos dos refugiados. Ora, as violações de direitos humanos e o fluxo de refugiados indicam ser indissociáveis, fazendo com que os instrumentos do regime internacional dos direitos humanos devam prover sustento aos regimes internacional, regional e nacional de proteção aos refugiados ${ }^{34}$.

No caso em tela do judoca congolês, por exemplo, é preciso haver remissão aos direitos resguardados pela Convenção Contra a Tortura e Outros Tratamentos ou Penas Cruéis, Desumanos ou Degradantes ${ }^{35}$, de 1984, a fim de fundamentar a violação de direitos humanos que lhes foi imposta. O artigo $3^{\text {o }}$ dessa Convenção determina que:

1. Nenhum Estado Parte procederá à expulsão, devolução ou extradição de uma pessoa para outro Estado quando houver razões substanciais para crer que a mesma corre perigo de ali ser submetida à tortura.

2. A fim de determinar a existência de tais razões, as autoridades competentes levarão em conta todas as considerações pertinentes, inclusive, quando for o caso, a existência, no Estado em questão, de um quadro de violações sistemáticas, graves e maciças de direitos humanos.

\footnotetext{
${ }^{30}$ Tradução livre do trecho original em espanhol "situaciones caracterizadas por una violencia tan indiscriminada y generalizada al punto de afectar a grandes grupos de personas o a poblaciones enteras obligándolas a huir". ACNUR, Resumen..., op. cit., p. 4.

31 Ibidem, p. 4-5.

32 TURK, op. cit.

33 ACNUR, Resumen..., op. cit., p. 2.

${ }^{34}$ MENEZES, Thais Silva. Direitos Humanos e Direito Internacional dos Refugiados: uma relação de complementaridade.

35 A Convenção Contra a Tortura e Outros Tratamentos ou Penas Cruéis, Desumanos ou Degradantes foi ratificado pelo Brasil através do decreto no 40 de 15 de fevereiro de 1991.
} 
Isto é, o Estado que ratifica a Convenção acima citada não pode negar proteção a quem foge do risco de ser submetido à tortura, o qual pode ser identificado em um contexto de violações sistemáticas de direitos humanos, como ocorre na RDC. Portanto, visando à completude de proteção para pessoas que se encontram em situação de refúgio, é preciso haver uma compreensão difusa do instituto que considere os demais termos de garantia de direitos. A definição de refugiados é de extrema importância para proteção, de modo que as questões relativas aos solicitantes de refúgio e aos solicitados sejam norteadas por um marco de direitos humanos que vai além da Convenção de Genebra e da Lei $9.474 / 97^{36}$.

\section{Conclusão}

Os novos desafios de caráter global que, hodiernamente, colocam em xeque a proteção humanitária em diversos aspectos, recordam que a forma com que o ser humano interage com o mundo e com seus semelhantes é fluída e está em constante alteração. Traz-se este pensamento para a esfera normativa do refúgio e percebe-se que é, pois, cada vez mais difícil adequação estrita dos casos empíricos, mesmo com a definição mais ampla adotada pelo Brasil.

O presente artigo procurou mostrar um das tantas situações em que é necessário um exercício de interpretação mais inclusiva e abrangente do conjunto normativo acerca da temática do refúgio no Brasil, a partir do caso concreto de um judoca congolês que tem sua vida, sua liberdade e sua segurança em risco em seu país de origem. Um caso em que a vulnerabilidade e a necessidade de proteção urgem, mas que, ainda assim, sua narrativa não pareia com o ordenamento jurídico nacional para os casos de reconhecimento de refúgio pelo Governo brasileiro atualmente.

Posiciona-se este artigo pelo reconhecimento do status de refugiado de Nkanza, demonstrando que as noções de perseguição por grupo social e da configuração de grave e generalizada violação de direitos humanos no país de origem do solicitante, além da Convenção Contra a Tortura e dos demais compromissos firmados pelo Brasil em matéria de Direito Internacional dos Direitos Humanos, somados e articulados, fundamentam, em entendimento do autor, a vulnerabilidade do caso e sustentam uma resposta positiva quanto à sua adequação ao instituto protetivo do refúgio.

Isto posto, reforça-se que, para que o Estado brasileiro mantenha um posicionamento sólido e vanguardista no que tange ao direito dos refugiados, tendo como base fundamental o Direito Internacional dos Direitos Humanos,

36 PLENDER, Richard; MOLE, Nuala. Beyond the Geneva Convention: constructing a de facto right of asylum from international human rights instruments, p. 81-105. 
é preciso que esteja permanentemente sensível aos novos fluxos de pessoas, revisando, sempre que necessário, seus mecanismos de identificação e proteção.

\section{Bibliografia Final}

ACNUR. Manual de Procedimentos e Critérios para a Determinação da Condição de Refugiado: de acordo com a Convenção de 1951 e o Protocolo de 1967 relativos ao estatuto dos refugiados. 2011.

- Resumen de las conclusiones sobre la interpretación de la definición ampliada de refugiado de la Declaración de Cartagena de 1984. 2014. Disponível em: <http://www.acnur.org/t3/que-hace/proteccion/declaracion-de-cartagenasobre-los-refugiados/> . Acesso em: 20.07.2014.

ALMEIDA, Guilherme Assis de. A Lei 9.474/97 e a definição ampliada de refugiado: breves considerações. In ARAUJO, Nadia de; ALMEIDA, Guilherme Assis de (coordenadores). O Direito Internacional dos Refugiados: uma perspectiva brasileira. Rio de Janeiro: Renovar, 2001.

MENEZES, Thais Silva. Direitos Humanos e Direito Internacional dos Refugiados: uma relação de complementaridade. In Proceedings of the 3rd ENABRI $20113^{\circ}$ Encontro Nacional ABRI 2011. São Paulo, 2011. Disponível em: <http://www. proceedings.scielo.br/scielo.php?script=sci_arttext\&pid=MSC00000001220110 00300050\&lng $=$ en\&nrm=iso > . Acesso em: 20.07.2014.

PLENDER, Richard; MOLE, Nuala. Beyond the Geneva Convention: constructing a de facto right of asylum from international human rights instruments. In NICHOLSON, Frances; TWOMEY, Patrick (orgs.). Refugee Rights and Realities: evolving international concepts and regimes edited. Nova lorque: Cambridge University, 1999.

RAMOS, André de Carvalho. Asilo e Refúgio: semelhanças, diferenças e perspectivas. In 60 Anos de ACNUR: Perspectivas de futuro. André de Carvalho, Gilberto Rodrigues e Guilherme Assis de Almeida (orgs.). São Paulo: Editora CL-A Cultural, 2011.

SILVA, Cesar Augusto da; RODRIGUES, Viviane Mozine. Refugiados: Os Regimes Internacionais de Direitos Humanos e a Situação Brasileira. In Direitos Humanos e refugiados. Cesar Augusto S. da Silva (org.). Dourados: Ed. UFGD, 2012.

WEBER, Max. Ciência e Política: duas vocações. São Paulo: Cultrix, 2011.

WHITE, Hyden. El contenido de la forma: narrativa, discurso y representación historica. Barcelona: Edições Paidos, 1992. 


\section{Abstract}

\section{Refuge and reality: challenges of the expanded definition of refuge in the light of the claims in Brazil}

This article aims to analyze how the concept of grave and generalized violation of Human Rights and the definition of refuge are interrelated in processes of formal recognition of refuge status in Brazilian individual cases of violence. This article aims to propose a more inclusive and wide interpretation of the normative set concerning refugee issues, taking as reference the case study of an athlete from Democratic Republic of Congo whose life, liberty and security were in danger in his country of origin. However, in a first sight, this case does not match with the Brazilian legal order concerning the refugee status determination. Therefore, the primary focus of this work is to analyze some issues raised by the gaps in the legal framework applicable to this subject.

Keywords: refuge, human rights, refugee law, international human rights law, Democratic Republic of Congo.

Recebido para publicación en 31/08/2014.

Aceptado para publicación en 06/11/2014.

Received for publication in August, 31 ${ }^{\text {th }}, 2014$. Accepted for publication in November, 06 ${ }^{\text {th }}, 2014$.

ISSN impresso: 1980-8585

ISSN eletrônico: 2237-9843

http://dx.doi.org/10.1590/1980-85852503880004308 